7. The alkali-labile link in ribonucleic acids is at $\mathrm{C}^{\prime}-5$.

8. Ribonuclease hydrolyses certain esters of pyrimidine ribonucleoside $3^{\prime}$ - (or $2^{\prime}$-) phosphates.

9. Four dinucleoside monophosphates have been prepared by hydrolysis with ribonuclease followed by phosphomonoesterase.

10. A structure for ribonucleic acid has been proposed which satisfies these results on the basis of an unbranched chain.

\title{
REFERENCES
}

Brown, D. M., Dekker, C. A. \& Todd, A. R. (1952). J.chem. Soc. p. 2715.

Brown, D. M. \& Todd, A. R. (1952). J. chem. Soc. p. 44.

Carter, C. A. \& Cohn, W. (1950). J. Amer. chem. Soc. 72 , 2604.

Cavalieri, L. F., Kerr, S. E. \& Angelos, A. (1951). J. Amer. chem. Soc. 73, 2567.

Cohn, W. E. (1951). J. cell. comp. Physiol. 38, suppl. 1, 21.

Cohn, W. E. \& Volkin, E. (1951). Nature, Lond., 167, 483.

Gordon, A. H. \& Reichard, P. (1951). Biochem. J. 48, 569.

Gulland, J. M., Barker, G. R. \& Jordan, D. O. (1945). Ann. Rev. Biochem. 14, 175.
Levene, P. A. (1909). Biochem. Z. 17, 120.

Levene, P. A. \& Simms, H. S. (1925). J. biol. Chem. 65, 514. Markham, R. \& Smith, J. D. (1949). Biochem. J. 45, 294.

Markham, R. \& Smith, J. D. (1950). Biochem. J. 46, 513.

Markham, R. \& Smith, J. D. (1951 a). Biochem. J. 49, 401.

Markham, R. \& Smith, J. D. (1951 b). Nature, Lond., 168, 406.

Markham, R. \& Smith, J. D. (1952). Biochem. J. 52, 552.

Schmidt, G., Cubiles, R. \& Thannhauser, S. J. (1947). Cold Spr. Harb. Symp. quant. Biol. 12, 161.

Smith, J. D. \& Markham, R. (1950). Biochem. J. 46, 509.

Wyatt, G. R. (1951). Biochem. J. 48, 584.

\section{The Structure of Ribonucleic Acid}

\section{THE END GROUPS, THE GENERAL STRUCTURE AND THE NATURE OF THE 'CORE'}

\author{
BY R. MARKHAM AND J. D. SMITH \\ Agricultural Research Council, Plant Virus Research Unit, Molteno Institute, \\ University of Cambridge
}

\section{(Received 20 February 1952)}

Although much is known about the size and the various physical properties of the deoxyribonucleic acids, there is less information about the ribonucleic acids (RNA), largely because they are more difficult to prepare in an undegraded state, and to some extent also because they are easily and cheaply available commercially in a partially degraded form. In addition, RNA from many animal sources is inevitably subjected to enzyme action during isolation. The plant viruses offer what is perhaps the most suitable material for such investigations; some of them will yield nucleic acid under the mildest treatment (Markham \& Smith, K. M., 1949). We also have some evidence that it is possible to prepare the RNA of yeast in a relatively undegraded form.

The determination of the molecular weights of such highly charged and asymmetrical molecules as those of the nucleic acids is a matter of extreme difficulty. Several attempts have been made to obtain this information for RNA (e.g. Tennent \& Vilbrant, 1943; Bacher \& Allen, 1950a), but it is likely that the results are only of the correct order of magnitude.

By more direct methods of a chemical nature, one can get an idea of the average molecular complexity.
The various titration studies fall in this category (e.g. Fletcher, Gulland \& Jordan, 1944), but these were made on partially degraded materials and probably involved some extra degradation as well. In this paper we shall describe how one can determine the average chain length of RNA and hence calculate the number of nucleotide residues per chain.

It has been known for some time that the course of digestion of RNA by ribonuclease stops before all the nucleotides are liberated. Kunitz (1940) found that $40 \%$ of his RNA was still precipitated by uranyl acetate after it had been digested to completion by the enzyme, while several workers have reported that a large fraction (about 10-25\%) of the digested RNA is unable to dialyse through cellophan film (Bernheimer \& Rodbart, 1948; Bacher \& Allen, 1950b), although the observation of Greenstein, Carter \& Chalkley (1947) to the contrary does not seem to have attracted much attention.

The 'non-dialysable' fraction of digested RNA has been called, among other names, the 'core' (e.g. Magasanik \& Chargaff, 1951), and we propose to adopt this convention in this paper, although we hope to demonstrate that its non-diffusibility 
through cellophan film is largely due to charge effects rather than to the actual size of its constituents. The core is in fact merely a mixture of polynucleotides having a structure similar to that of the ribonuclease-stable di- and tri-nucleotides which we have already described, i.e. a chain of purine nucleotide residues terminated at one end by a pyrimidine nucleotide residue.

\section{The proposed structure of ribonucleic acid}

We believe that the general structure of RNA is a series of unbranched chains of varying composition with the general features of the following diagram in which the nucleotide residues are represented by $A, G, C$ and $U$ for adenylic, guanylic, cytidylic and uridylic acid residues respectively:

$$
\begin{gathered}
\mathrm{A} C: U: C: U: C: C: \text { AGAG } C: U: C: C: \mathrm{AAG} U: \\
U: \mathrm{G} U: U: C: C: \mathrm{G} C: C: U: \mathrm{AGC}: \mathrm{A} !
\end{gathered}
$$

The exclamation mark after the terminal A denotes that it is a cyclic nucleotide. Each nucleotide is joined through a phosphate ester link on its C-2' (or $3^{\prime}$ ) to the adjacent residue on the right-hand side and through a similar link on $\mathrm{C}^{-5}{ }^{\prime}$ to its neighbour on the left (this nomenclature is the same as that used in the preceding paper). The bonds which are broken by ribonuclease are represented by colons, and those residues which can then be dephosphorylated by phosphomonoesterase are shown in italic type. Thus it will be seen that the chain shown above will give rise on complete ribonuclease digestien to fourteen pyrimidine mononucleotides, three dinucleotides, one trinucleotide, one tetranucleotide, one pentanucleotide and a cyclic purine nucleotide, and it will be seen that on subsequent phosphomonoesterase treatment all the pyrimidine nucleotide residues will be dephosphorylated. It necessarily follows from our theory of ribonuclease action (Markham \& Smith, 1952b) that the cyclic purine nucleotide could only be liberated if it were situated at one end of the chain. It must not, however, be thought that all chains are necessarily terminated by cyclic purine nucleotides. Pyrimidine nucleotides are also to be found in this position, and in commercially prepared RNA, where the average chain length has been reduced, probably by treatment with alkali, to only 6-8 units or even less, adenylic acids ' $a$ ' and ' $b$ ' and guanylic acids ' $a$ ' and ' $b$ ' (Carter, 1950) are also to be found at chain ends, as well as AG (Markham \& Smith, 1951). The core is composed of the tetra- and penta-nucleotides and possibly some of the trinucleotides.

A nucleic acid chain of the type depicted above is terminated on the left-hand side by a nucleoside residue linked through the hydroxyl group on C-2' (or $3^{\prime}$ ) to its neighbour by a phosphate ester link, and on the right by a nucleotide linked to the chain by its $5^{\prime}$-hydroxyl group. Residues of the latter type we shall call terminal groups and these may be determined in the following ways:

(a) If they are cyclic purine nucleotides linked to the rest of the chain through a pyrimidine nucleotide residue, the RNA is digested to completion with ribonuclease and the $A$ ! and $G$ ! isolated chromatographically (it will be noted that in the isopropanolammonia solvent (solvent 1, Markham \& Smith, $1952 a$ ) these are to be found in bands $5 a$ and 6 , well ahead of any other possible constituents and consequently very small amounts may be detected in large quantities of digest).

(b) If the terminal groups are nucleoside $2^{\prime}$ - or 3'-phosphates they may be dephosphorylated by phosphomonoesterase. On subsequent hydrolysis of the RNA with sodium hydroxide these groups will then yield nucleosides while all the others will yield nucleotides. In solvent 1 the latter appear in bands 2 and 4, while the nucleosides run well ahead and may then be separated and identified. Some of these terminal groups may also be determined on ribonuclease digests. For example, a terminal purine nucleoside $2^{\prime}$ - (or $3^{\prime}$ )-phosphate, if linked to a pyrimidine nucleotide residue, will be liberated as a nucleotide on ribonuclease digestion and may then be separated from the digest and identified (Markham \& Smith, 1951).

(c) Terminal cyclic pyrimidine nucleotides will not be detected by any of these methods as they are not attacked by phosphomonoesterase, and ribonuclease digestion does not distinguish them from other pyrimidine residues. We know of no method of revealing such end groups.

(d) Terminal cyclic purine nucleotides linked through a purine nucleotide residue to the chain will appear in ribonuclease digests as polynucleotides containing only purines. We have not attempted the identification of such substances as they must be present in very small quantities.

Another aspect of structure which is of interest is the distribution of the various nucleotides in the polynucleotides which are found in ribonuclease digests. The quantitative isolation of analogous pairs of substances such as $A U$ and AC, or GU and GC, or AU and GU gives a measure of the frequencies with which individual nucleotides occur in certain possible positions in the nucleic acid chain. In this way we have shown for two different RNA's that there is a certain amount of order in the arrangement of the purine nucleotides in the chains.

\section{METHODS AND MATERIALS}

The methods and materials used were essentially the same as those described in the previous papers in this series (Markham \& Smith, 1952 $a, b$ ). For convenience we shall list again the various chromatographic systems used: (1) $70 \%$ isopropanol-water $(v / v)$ with $\mathrm{NH}_{3}$ in the vapour 
phase; (2) sat. $\left(\mathrm{NH}_{4}\right)_{2} \mathrm{SO}_{4}, 80$ parts, isopropanol, 2 parts; $0.5 \mathrm{M}$-sodium acetate, 18 parts $(v / v / v)$; (3) $n$-butanol saturated with water, 90 parts; formic acid, 10 parts $(\nabla / v)$; (4) isopropanol, $170 \mathrm{ml}$.; conc. $\mathrm{HCl}, 44 \mathrm{ml}$.; water to $250 \mathrm{ml}$. Solvent 1 separates the products of ribonuclease digestion into a number of bands which we have numbered 1 to 6 in order of $R_{F}$ values. The details of this separation and of the paper electrophoresis are to be found in the previous papers.

\section{Digestion of $R N A$ with ribonuclease}

In all experiments to be described digestion with ribonuclease was carried to completion. Hydrolysis was at $5^{\circ}$ usually with $0.1 \mathrm{mg}$. ribonuclease $/ \mathrm{ml}$. and constantly adjusted to pH 7.6, until chromatographic analysis showed that all the cyclic pyrimidine nucleotides had been hydrolysed. The hydrolysis of the latter by ribonuclease proceeds much more slowly than the breakdown of the internucleotide linkages so that the disappearance of cyclic pyrimidine nucleotides marks the end of ribonuclease digestion.

\section{Isolation of the 'core'}

RNA completely digested with ribonuclease was dialysed in cellophan sacs against distilled water with stirring for about $48 \mathrm{hr}$. at which time the rate of loss of material from the sac was extremely small. Samples of such cores were usually treated again with ribonuclease and examined chromatographically to ensure that no undegraded RNA remained.

\section{The isolation and estimation of purine nucleotides in ribonuclease digests}

A ribonuclease digest of RNA (8-16 mg.) was placed in a line across the top of a sheet of filter paper (Whatman no. 3) and developed in solvent 1 . A ! and $G$ ! were found in bands 6 and $5 a$, and their identification has already been described (Markham \& Smith, 1952a). The bands were cut out, eluted, concentrated and run as a chromatogram in solvent 2 . The spots of $A$ ! and $G$ ! were eluted and estimated spectrophotometrically.

Adenylic acids ' $a$ ' and ' $b$ ' were found in band 4 of the chromatogram using solvent 1 , together with the pyrimidine nucleotides, and were separated from the latter by running in solvent 2. Guanylic acids ' $a$ ' and ' $b$ ' were in band 2 together with AC, AU and certain trinucleotides. They were isolated using solvent 2 , in some cases after a preliminary fractionation by paper electrophoresis. The adenylic and guanylic acids were identified by chromatography in solvents 1,2 and 4, by their ultraviolet light absorption spectra and by their movement on paper electrophoresis at $\mathrm{pH} 3 \cdot 5$. On hydrolysis with $\mathrm{N}-\mathrm{HCl}$ for $1 \mathrm{hr}$. at $100^{\circ}$ they were quantitatively converted to adenine and guanine respectively.

\section{The estimation of end groups in $R N A$ and the 'core' by phosphomonoesterase treatment}

The intact RNA and the core were incubated with purified prostate phosphomonoesterase (Markham \& Smith, 1952b) at $37^{\circ}$ in $0.1 \mathrm{M}$-acetate buffer, $\mathrm{pH} 5$, for sufficient time to ensure the complete liberation of the terminal phosphoryl groups. This time was estimated from the rate of dephosphorylation of solutions of pure adenylic and guanylic acids by the enzyme preparation, and under these conditions the rate of dephosphorylation of cyclic nucleotides was neg- ligible. On further incubation of the digests no more phosphate was liberated and chromatograms in solvent 2 showed no evidence of phosphodiesterase or of ribonuclease activity (although by using a much greater enzyme concentration and incubating at $\mathrm{pH} 7.5$ and $55^{\circ}$, it was possible to demonstrate that the enzyme did contain a small amount of ribonuclease). $\mathrm{NaOH}$ was then added to give a concentration of about $0.3 \mathrm{~N}$, and the digest incubated at $37^{\circ}$ for 4-5 hr. when all the internucleotide links were hydrolysed to give mononucleotides plus the nucleosides derived from the dephosphorylated terminal groups. Intact RNA treated in this way with $\mathrm{NaOH}$ gave no nucleosides.

The nucleosides were isolated from these digests by neutralizing them with acetic acid, and chromatographing the solution in solvent 1 on Whatman no. 3 paper. In this solvent the nucleosides were to be found in two bands moving ahead of the nucleotides. The slower of the two contained guanosine, and the other adenosine, cytidine and uridine. The guanosine was further purified by chromatography in solvent 2. This solvent also separated adenosine from the mixture of adenosine, cytidine and uridine, while solvent 3 resolved cytidine from adenosine and uridine. Uridine could thus be estimated by difference. All estimations were made spectrophotometrically.

\section{RESULTS}

\section{The end groups of $R N A$}

Certain of the terminal phosphorylated groups have been identified and quantitatively estimated in two ribonucleic acids, that prepared from yeast by a mild method (YNA 1) and the nucleic acid isolated from turnip yellow mosaic virus at neutral $\mathrm{pH}$ (Markham \& Smith, 1952b). The end groups estimated comprise the purine nucleotides (A !, G ! and the adenosine and guanosine 2' - and 3'-phosphates) linked to the nucleic acid chain through a pyrimidine nucleotide residue, all of which were isolated from ribonuclease digests, and all non-cyclic purine and pyrimidine end groups which were isolated as nucleosides after treatment of the nucleic acid with phosphomonoesterase and alkali. It will be appreciated that, in the estimation of the latter type of end group, contamination of the phosphomonoesterase preparations with ribonuclease could give spuriously high values for pyrimidine nucleotide end groups, while the presence of diesterase would affect the values for both purine and pyrimidine nucleotides. The control experiments described earlier eliminated these possibilities.

Table 1 lists the types of terminal groups found and their relative abundance in the two nucleic acids. Some of these occur in very small amounts and we would not claim a high degree of precision in their estimation. Remembering that certain types of phosphorylated end groups are excluded from this list, and that the purine nucleoside $2^{\prime}$ - and $3^{\prime}$ phosphates estimated using phosphomonoesterase include the end groups of this type also found in ribonuclease digests, it is possible to calculate 
Table 1. The terminal groups of ribonucleic acids of yeast and the turnip yellow mosaic virus

(Amounts are in moles/100 moles of nucleotide residues in the intact nucleic acids. The colon denotes a bond which is broken by ribonuclease, and italic type shows that the end group is attacked by phosphomonoesterase.)

End group
$\begin{gathered}: \mathrm{A} ! \\ : \mathrm{G} ! \\ : A \\ : G \\ A \\ G \\ C \\ U\end{gathered}$

\begin{abstract}
Method of determination
Complete ribonuclease digestion

Complete ribonuclease digestion

Complete ribonuclease digestion

Complete ribonuclease digestion
\end{abstract}

Phosphomonoesterase $+\mathrm{NaOH}$ hydrolysis

Phosphomonoesterase $+\mathrm{NaOH}$ hydrolysis

Phosphomonoesterase + NaOH hydrolysis

Phosphomonoesterase $+\mathrm{NaOH}$ hydrolysis

$\begin{array}{cc}\text { Turnip yellow } & \begin{array}{r}\text { Yeast } \\ \text { mosaic virus } \\ \text { nucleic acid } \\ \text { acid }\end{array} \\ 0.16 & 0.88 \\ 0.20 & 1 \cdot 16 \\ \text { None } & <0.58 \\ \text { detected } & \\ \text { None } & <0.26 \\ \text { detected } & \\ 0.17 & 1.06 \\ 0.18 & 1.40 \\ 0.97 & 1.81 \\ 0.22 & 1.90\end{array}$

maximum mean chain lengths for the two nucleic acids. These are twelve and fifty-three residues for the yeast and virus nucleic acids respectively.

\section{The distribution of nucleotides among the ribonuclease-resistant digestion products}

The mononucleotides, dinucleotides and certain of the trinucleotides were quantitatively isolated from complete ribonuclease digests of the two nucleic acids by methods we have described in detail elsewhere (Markham \& Smith, 1952a,b). Each polynucleotide was analysed for its component purines and pyrimidines. The pyrimidine nucleotides were found in band 4 of chromatograms run in solvent 1 together with adenylic acid if present. The absence of other components in this band (shown by chromatography in solvent 2 and by paper electrophoresis) made it possible to estimate the free cytidylic and uridylic acids by chromatography in solvent 4 after hydrolysis for $1 \mathrm{hr}$. at $100^{\circ}$ in $\mathrm{N}-\mathrm{HCl}$ which converts the adenylic acid to adenine.

YNA (1) and the 'cores' from turnip-yellowmosaic-virus nucleic acid and a second preparation of a yeast ribonucleic acid (YNA 2) were analysed for their purines and pyrimidines (Table 2). It should be noted that YNA (1) and YNA (2) differed in composition. (We have noted this for several preparations.)

In Tables 3 and 4 the results are arranged to show the distribution of the two pyrimidine nucleotides among the digestion products, and Table 5 gives similar data for adenylic and guanylic acids.

Both nucleic acids have the following features in common: (a) About 30-45\% of the uridylic and cytidylic acid residues are liberated in complete digests as the free nucleotides, while 3-5\% appear as AC and AU. A considerable proportion of the nucleotides is present in polynucleotides containing three to five residues which have not yet been isolated individually. (b) The ratios of the two pyrimidine nucleotides present in pairs of analogous substances such as $\mathrm{C}$ and $\mathrm{U}, \mathrm{GC}$ and GU, and in the 'core' are in all cases very close to those found in the whole nucleic acids.

Table 2. Molar ratios of the nucleotides (to an arbitrary total of 4) of the nucleic acids of yeast and the turnip yellow mosaic virus

\begin{tabular}{|c|c|c|c|c|}
\hline & $\begin{array}{l}\text { Yeast } \\
\text { ribo- } \\
\text { nucleic } \\
\text { acid } \\
(1)\end{array}$ & $\begin{array}{c}\text { Core } \\
\text { from } \\
\text { yeast } \\
\text { RNA } \\
(2)\end{array}$ & $\begin{array}{c}\text { Turnip } \\
\text { yellow } \\
\text { mosaic } \\
\text { virus } \\
\text { RNA }\end{array}$ & $\begin{array}{c}\text { Core from } \\
\text { turnip } \\
\text { yellow } \\
\text { mosaic } \\
\text { virus RNA }\end{array}$ \\
\hline $\begin{array}{l}\text { Adenylic acid } \\
\text { Guanylic acid } \\
\text { Cytidylic acid } \\
\text { Uridylic acid }\end{array}$ & $\begin{array}{l}1 \cdot 15 \\
0 \cdot 97 \\
0 \cdot 78 \\
1 \cdot 10\end{array}$ & $\begin{array}{l}1 \cdot 32 \\
1 \cdot 62 \\
0 \cdot 49 \\
0 \cdot 56\end{array}$ & $\begin{array}{l}0.91 \\
0 \cdot 69 \\
1.53 \\
0.89\end{array}$ & $\begin{array}{l}1 \cdot 42 \\
1 \cdot 34 \\
0 \cdot 75 \\
0 \cdot 49\end{array}$ \\
\hline
\end{tabular}

(c) The proportions of the two purine nucleotides found in the dinucleotide fraction, the 'core' and the cyclic purine nucleotides differ from each other and from those of the whole nucleic acid.

\section{The 'core' of $R N A$}

'Cores' prepared from the ribonucleic acids of yeast (YNA 2) and turnip yellow mosaic virus were analysed for the bases (Table 2) and contained respectively 26 and $31 \%$ of the bases as pyrimidines (on a molar basis).

The terminal phosphorylated groups of the YNA 'core' were identified in the following way. The 'core' was treated with phosphomonoesterase to dephosphorylate the terminal groups and the digest hydrolysed with sodium hydroxide. Terminal residues were thus converted to nucleosides and other residues to nucleotides. The alkali digest was neutralized with acetic acid and run on a twodimensional chromatogram in solvents 1 and 2. Pyrimidine nucleosides and the ' $a$ ' and ' $b$ ' forms of adenylic and guanylic acids were the only substances found. It follows that all the pyrimidine nucleotides 
Table 3. The distribution of cytidylic and uridylic acid among some of the products of the complete ribonuclease digestion of yeast $R N A(1)$

(All values are in moles/100 moles of nucleotide residues in the intact RNA.)

\begin{tabular}{|c|c|c|c|c|}
\hline Substance & $\begin{array}{l}\text { Cytidylic } \\
\text { acid } \\
\text { present }\end{array}$ & Substance & $\begin{array}{l}\text { Uridylic } \\
\text { acid } \\
\text { present }\end{array}$ & $\begin{array}{l}\text { Molar ratio } \\
\text { uridylic acid/ } \\
\text { cytidylic acid }\end{array}$ \\
\hline $\begin{array}{l}\text { C } \\
\text { AC } \\
\text { Whole RNA }\end{array}$ & $\begin{array}{c}5 \cdot 63 \\
0 \cdot 77 \\
19 \cdot 5\end{array}$ & $\begin{array}{l}\text { U } \\
\text { AU } \\
\text { Whole RNA }\end{array}$ & $\begin{array}{r}8 \cdot 41 \\
1 \cdot 02 \\
27 \cdot 5\end{array}$ & $\begin{array}{l}1 \cdot 49 \\
1 \cdot 32 \\
1 \cdot 41\end{array}$ \\
\hline
\end{tabular}

Table 4. The distribution of cytidylic and uridylic acid among some of the products of the complete ribonuclease digestion of turnip-yellow-mosaic-virus nucleic acid

(All values are in moles/100 moles of nucleotide residues.)

\begin{tabular}{|c|c|c|c|c|}
\hline Substance & $\begin{array}{c}\text { Cytidylic } \\
\text { acid } \\
\text { present }\end{array}$ & Substance & $\begin{array}{l}\text { Uridylic } \\
\text { acid } \\
\text { present }\end{array}$ & $\begin{array}{l}\text { Molar ratio } \\
\text { uridylic acid// } \\
\text { cytidylic acid }\end{array}$ \\
\hline C & $15 \cdot 3$ & $\mathbf{U}$ & $9 \cdot 6$ & $0 \cdot 63$ \\
\hline $\mathbf{A C}$ & $1 \cdot 86$ & $\mathbf{A U}$ & $1 \cdot 06$ & $0 \cdot 57$ \\
\hline GC & 0.67 & GU & 0.43 & 0.65 \\
\hline AAC & 0.25 & AAU & $0 \cdot 15$ & $0 \cdot 60$ \\
\hline The 'core' & $4 \cdot 02$ & The 'core' & $2 \cdot 64$ & 0.65 \\
\hline Average ratio & - & - & - & $0.62 \pm 0.035$ \\
\hline Whole nucleic acid & $38 \cdot 3$ & Whole nucleic acid & $22 \cdot 3$ & 0.58 \\
\hline
\end{tabular}

in the 'core' are in a terminal position and these are the only terminal groups. The polynucleotides in the 'core' thus have the structure common to all the ribonuclease-resistant polynucleotides, that is a chain of purine nucleotide residues terminated by a pyrimidine nucleotide. With this knowledge one may calculate the mean chain length from the proportions of pyrimidine nucleotides in the 'core'. For the virus nucleic acid 'core' this is 3.2 residues and for YNA (2) 'core' 3.9 residues.

Table 5. The distribution of the two purines in fractions of complete ribonuclease digests of yeast ribonucleic acid (1) and turnip-yellow-mosaic-virus nucleic acid

$\begin{array}{lcc}\text { Ratio } & \begin{array}{c}\text { ribonucleic } \\ \text { acid (1) }\end{array} & \begin{array}{c}\text { mosaic virus } \\ \text { nucleic acid }\end{array} \\ \text { A/G in whole nucleic acid } & \mathbf{1 \cdot 1 8} & \mathbf{1 . 3 2} \\ \text { A/G in 'core' } & - & 1 \cdot 06 \\ \text { A!/G! } & 0.75 & 0 \cdot 81 \\ \text { AC/GC } & - & 2 \cdot 78 \\ \text { AU/GU } & - & 2 \cdot 44\end{array}$

\section{Dialysis of the 'core'}

If the 'core' is placed in a cellophan sac and dialysed against water the polynucleotides diffuse out extremely slowly. The isolation of 'core' of course depends on this fact, and these 'cores' have already been dialysed against water for considerable periods. If, however, the water outside the sac is replaced by $2 \mathrm{M}$-sodium chloride the rate of loss of polynucleotides from the sac is greatly increased and with rapidly stirred dialysis against changes of concentrated sodium chloride solution almost all the material passed from the sac in a few hours.

\section{DISCUSSION}

In the first two papers of this series (Markham \& Smith, 1952 $a, b$ ) we have shown that the specificity of ribonuclease is such that it breaks ester linkages of pyrimidine nucleoside $2^{\prime}$ - (or $3^{\prime}$ )-phosphates joining adjacent ribose residues presumably by a $2^{\prime}: 5^{\prime}$-internucleotide link, ${ }^{*}$ to give rise to mono-, diand tri-nucleotides, and that there is no reason to postulate a branched structure to explain the formation of these substances. The only other position in which branching could occur is in the so-called 'core'. Now this core has quite definite chemical properties which fix limits on its structure. One in every three or four residues on the average is terminal and bears a secondary phosphoric acid $-\mathrm{OH}$ group. We have shown, in agreement with the findings of Schmidt et al. (1951), that the latter is always associated with pyrimidine nucleotide residues. The whole core is hydrolysed by alkali to give nucleoside $2^{\prime}$ - or $3^{\prime}$-phosphates (or in the case of the purine nucleotides, both the ' $a$ ' and the ' $b$ ' forms) so that the $2^{\prime}$ or $3^{\prime}$ group in each residue is phosphorylated. It is difficult to visualize a chain branching on sugar residues which could have all these properties, bearing in mind that any postulated structure must allow the formation of $2^{\prime}: 3^{\prime}$ cyclic phosphates to account for the alkali lability of the internucleotide link. Fortunately it is not necessary to postulate any branching to explain the existence

* In the two preceding papers we have assumed that the link is $3^{\prime}-5^{\prime}$ by analogy with deoxyribonucleic acid. Experiments which we have since done on the latter make us suspect that if the two structures had this similarity deoxyribonuclease would digest RNA. 
of the core, for, as we have shown, it can diffuse quite readily through cellophan film provided that sufficient salt is present in the solution. Because of this there is no reason to suppose that it is anything other than a mixture of short chains, about three or four purine nucleotide residues in length, terminated by a pyrimidine nucleoside $2^{\prime}$ - (or $3^{\prime}$ )-phosphate joined to the rest of the chain by its $5^{\prime}$-hydroxyl group. That is to say the core is only a mixture of polynucleotides having the same general properties as the ribonuclease-stable di- and tri-nucleotides. In the absence of salts these polynucleotides associate or are prevented by charge effects from dialysing, while in the presence of salts these relatively small molecules can diffuse quite readily through cellophan film. This explains the observations of Greenstein et al. (1947) on the (apparent) activating effect of sodium chloride on the rate of ribonuclease action, and also suggests that their nucleic acid was badly degraded even before they added the enzyme. The non-dialysability in distilled water of polynucleotides is not surprising as they are covered with charged groups. The final picture of RNA would seem to be an unbranched chain.

We have attempted to measure the length of the RNA chains by revealing their end groups. While we do not claim great precision for the estimate of the chain lengths which we have made, especially as we cannot hope to reveal those ends which consist of cyclic pyrimidine nucleotide residues, it is obvious from the results that the chains are quite short and of many kinds. This conclusion follows not only from the frequency of the observed end groups, but also from the relative abundance of the large number of polynucleotides which we have described in the previous papers, while there must be several trinucleotides as yet unidentified, not to mention the tetra- and penta-nucleotides comprising much of the core.

The distribution of the pyrimidine nucleotides among the various mono-, di- and poly-nucleotides of the two different types of RNA which we have investigated shows a remarkable consistency which gives some indication of the structural arrangement in the chains. The end products of ribonuclease digestion, with the exception of terminal groups, are all of a type which can be represented by the formulae $\mathrm{Pu} C$ and $\mathrm{Pu} U$, in which $\mathrm{Pu}$ is $n$ purine nucleotide residues $(n \geqslant 0$; if $n=0, \mathrm{Pu} U$ is free uridylic acid). For any pair $\mathrm{Pu} C$ and $\mathrm{Pu} U$ having the $\mathrm{Pu}$ part of the molecules identical, we have found that the molar ratio $\mathrm{Pu} C / \mathrm{Pu} U$ has a value approximating closely to the ratio of cytidylic acid to uridylic acid in the intact nucleic acid and in the 'cores'. These ratios are shown for some of the polynucleotides in the two RNA's in Tables 3 and 4. Bearing in mind the specificity of ribonuclease action, the occurrence of a pyrimidine nucleotide residue in a substance such as $\mathrm{PuC}$ or $\mathrm{Pu} U$ fixes to some extent its position in the intact nucleic acid. Thus the cytidylic acid residue in $\mathrm{Pu} C$ can only occupy one of the positions shown as $(a),(b)$ and $(c)$ (here use has been made of the notation introduced earlier in this paper, while $R$ represents any residue and $X$ a pyrimidine nucleotide)

$$
X: \mathrm{Pu} C: \mathbf{R} \quad, X: \mathrm{Pu} C \quad \mathrm{Pu} C: \mathrm{R}
$$

and similarly for $\mathrm{Pu} U$. In the structures of this type $U$ and $C$ would appear to be interchangeable. This materially reduces the amount of isomerism possible in the nucleic acid chains. The distribution of the purine nucleotide residues, on the other hand, is of a different type as the ratios of $A / G$ in the core, the dinucleotide fraction and the intact RNA's differ widely from each other (Table 5).

\section{SUMMARY}

1. Two methods have been developed for the identification of nucleotides which occupy end positions in ribonucleic acid chains and bear terminal phosphoryl groups.

2. The cyclic nucleotides adenosine $2^{\prime}: 3^{\prime}$-monohydrogen phosphate and guanosine $2^{\prime}: 3^{\prime}$-monohydrogen phosphate, and adenylic, guanylic, cytidylic and uridylic acids have been recognized as end groups in the ribonucleic acids of yeast and turnip yellow mosaic virus.

3. Estimates have been made of the proportions of these terminal groups present in the two nucleic acids. It is concluded that ribonucleic acid consists of mixtures of many kinds of comparatively short chains.

4. The frequencies with which the nucleotides occur among the ribonuclease-resistant digestion products has been studied. The distribution of cytidylic and uridylic acids among the positions occupied by the pyrimidine nucleotides in the intact nucleic acid chain appears to be random. That of guanylic and adenylic acids, however, is not random.

5. The 'core' of ribonucleic acids, that is the fraction of the ribonuclease digest which does not dialyse into water through cellophan film, has been shown to be readily dialysable against salt solutions. It is a mixture of polynucleotides about three to five residues in length and each polynucleotide is a chain of purine nucleotides terminated by a pyrimidine nucleotide residue, with the terminal phosphoryl group on carbon atom $2^{\prime}$ or $3^{\prime}$. The components of the core have the same structure as the other ribonuclease-resistant polynucleotides.

We should like to express our thanks to Miss E. M. Dunkerley, Mr V. Massey, Mr R. K. Morton and Dr J. C. White for generous gifts of materials. Much valuable advice and criticism has been given by Prof. A. R. Todd, F.R.S., and Dr D. M. Brown. We should also like to thank Prof. D. Keilin, F.R.S., and Dr K. M. Smith, F.R.S., for their encouragement. 


\title{
REFERENCES
}

Bacher, J. E. \& Allen, F. W. (1950a). J. biol. Chem. 184, 511.

Bacher, J. E. \& Allen, F. W. (1950b). J. biol. Chem. 183, 633.

Bernheimer, A. W. \& Rodbart, M. (1948). J. exp. Med. 88, 149.

Carter, C. E. (1950). J. Amer. chem. Soc. 72, 2811.

Fletcher, W. E., Gulland, J. M. \& Jordan, D. O. (1944). J. chem. Soc. p. 33.

Greenstein, J. P., Carter, C. E. \& Chalkley, H. W. (1947). Cold Spr. Harb. Symp. quant. Biol. 12, 64.

Kunitz, M. (1940). J. gen. Physiol. 25, 15.
Magasanik, B. \& Chargaff, E. (1951). Biochim. Biophys. Acta, 7, 396.

Markham, R. \& Smith, J. D. (1951). Nature, Lond., 168, 406.

Markham, R. \& Smith, J. D. (1952a). Biochem. J. 52, 552.

Markham, R. \& Smith, J. D. (1952b). Biochem. J. 52, 558.

Markham, R. \& Smith, K. M. (1949). Parasitology, 39, 330.

Schmidt, G., Cubiles, R., Zöllner, N., Hecht, L., Strickler, N., Seraidarian, K., Seraidarian, M. \& Thannhauser, S. J. (1951). J. biol. Chem. 192, 715.

Tennent, H. G. \& Vilbrant, C. F. (1943). J. Amer. chem. Soc. $65,424$.

\section{The Orobanche Germination Factor}

\section{CONCENTRATION OF THE FACTOR BY COUNTER-CURRENT DISTRIBUTION}

\author{
By R. BROWN, A. D. GREENWOOD, A. W. JOHNSON, A. R. LANSDOWN, \\ A. G. LONG AND N. SUNDERLAND \\ Botany Department, University of Leeds, and Chemical Laboratory, University of Cambridge
}

(Received 27 February 1952)

The chromatographic purification of crude concentrates of the Orobanche germination stimulant, particularly partition chromatography on cellulose, has been described in an earlier paper (Brown, Greenwood, Johnson, Long \& Tyler, 1951b). The most active preparations thus obtained had activity values (Brown, Greenwood, Johnson \& Long, 1951 a) of 1-2 $\times 10^{5}$, and it seemed possible that they contained a high percentage of the pure stimulant. However, as these preparations were invariably resinous and as no convenient physical property of the stimulant was known by which its purity could be gauged, other methods of purification have been investigated to ascertain whether concentrates could be obtained with even higher activity values and possibly in a crystalline form.

Much of the present paper is concerned with purification of the Orobanche germination factor by partitioning between immiscible solvents, the choice of solvents being limited on the basis of earlier stability studies (Brown et al. 1951b) to those boiling below $120^{\circ}$ and neither strongly basic nor acidic.

In our earlier studies it was shown that the stimulant adsorbed on charcoal could best be eluted with chloroform-methanol and it has now been found that considerable purification of these crude eluates can be achieved by a further extraction of their aqueous solutions with ethyl acetate. This step has been included in all of our later purifications. Ethyl acetate was slightly superior to chloroform or ether for this extraction step.
The partition method of purification was extended to the use of counter-current methods, and many solvent systems were tried before a satisfactory distribution ratio of the active stimulant was achieved between the two immiscible phases. Some idea of the partition coefficient of a compound between heterogeneous solvent phases can be obtained from preliminary paper-strip chromatograms (Brown et al. 1951b). The relationship of the $R_{F}$ value in partition chromatography to the partition coefficient has been discussed by Martin \& Synge (1941), by Consden, Gordon \& Martin (1944) and by Craig (1950).

The mixture tert.-butanol (4)-light petroleum (b.p. $60-80^{\circ} ; 5$ )-acetone (4)-water (2) was eventually devised and this gave an appreciable concentration of the active material in the centre tubes of the counter-current apparatus, i.e. the partition was approximately equal between the two phases. tert.-Butanol was selected as the alcoholic component in order to cut down any esterification of lactone or acid groupings believed to be present in the molecule of the germination factor. The use of buffered solutions in the counter-current extractions to suppress such undesirable changes seemed inadvisable in view of the instability of the factor in alkaline or strongly acid solutions and the impossibility of carrying out the biological test in the presence of buffer solutions of the usual concentrations.

The purified stimulant obtained either by chromatography (Brown et al. 1951b) or by extrac. tion methods was only slightly soluble in water, and 